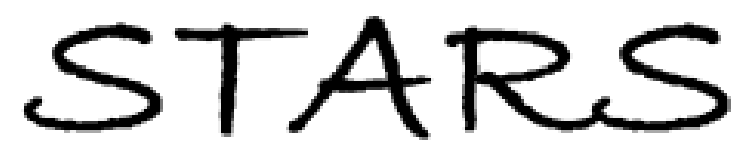

University of Central Florida

STARS

$1-1-2013$

\title{
Recalled Items and the American Board of Pathology Certification Examinations What Constitutes Cheating?
}

Diane Davis Davey

University of Central Florida

Find similar works at: https://stars.library.ucf.edu/facultybib2010 University of Central Florida Libraries http://library.ucf.edu

This Editorial Material is brought to you for free and open access by the Faculty Bibliography at STARS. It has been accepted for inclusion in Faculty Bibliography 2010 s by an authorized administrator of STARS. For more information, please contact STARS@ucf.edu.

\section{Recommended Citation}

Davey, Diane Davis, "Recalled Items and the American Board of Pathology Certification Examinations What Constitutes Cheating?" (2013). Faculty Bibliography 2010s. 3860.

https://stars.library.ucf.edu/facultybib2010/3860

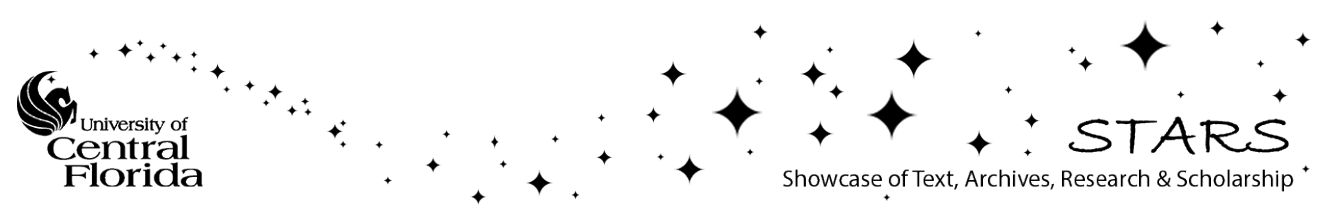




\title{
Recalled Items and the American Board of Pathology Certification Examinations
}

\author{
What Constitutes Cheating?
}

\author{
Diane Davis Davey, MD
}

W hat follows are conversations that might be heard in any pathology residency program around the country.

Resident A: So I just heard that you took the pathology board examination. I want to do everything possible to make sure that I pass the exam the first time. Will you help me figure out how to study the best way and what is on the exam? Do you have anything that lists what I need to know?

Resident B: I just took the exam last week but I am not sure that I can help that much.

Discussion: The American Board of Pathology (ABP) withheld certification from 3 candidates in 2012 because they either were in possession of "board remembrances material" at the time of the examination or were providing such remembrances on Internet sites. As a result, the ABP is working with pathology departments and chairs around the country to publicize honor codes and policies related to cheating. The mission of the ABP, a member of the American Board of Medical Specialties, "is to promote the health of the public and advance the practice and science of pathology by establishing voluntary certification standards and assessing the qualifications of those seeking to practice the specialty of pathology." ${ }^{1}$ This mission statement, which is found on the ABP Web site, is a reminder that public interests and expectations of professionalism must be considered in terms of honor code enforcement.

Resident A: I have heard that I need to become board certified within a few years for most jobs. My friend told me that the credentialing department where he has accepted a position will give him 3 years to pass the exam.

Accepted for publication January 10, 2013

Published as an Early Online Release April 24, 2013.

From the College of Medicine, University of Central Florida, Orlando, and the VA Medical Center, Orlando, Florida.

The author has no relevant financial interest in the products or companies described in this article.

doi: 10.5858/arpa.2012-0734-ED

Corresponding author: Diane Davis Davey, MD, College of Medicine, University of Central Florida, Health Sciences Campus of Lake Nona, 6850 Lake Nona Blvd, Room 406M, Orlando, FL 328227-7408 (e-mail: diane.davey@ucf.edu).
Discussion: Recognition as a board-certified pathologist is a major milestone in any pathologist's career. Certification means that a physician has demonstrated exceptional expertise in his specialty and has received a Gold Star. According to the American Board of Medical Specialties, the organization of specialty boards: "Patients, physicians, healthcare providers, insurers and quality organizations look for the Gold Star as the best measure of a physician's knowledge, experience and skills to provide quality healthcare within a given specialty." 2

Passing the board examination involves extensive study and mastery of the field, and most individuals invest a great deal of time and money. Because passing the board is so important to one's career, some residents understandably want to get advice from others who have successfully been certified. But what is appropriate and what would be considered cheating?

The following statements appear from the honor code to which all candidates for the ABP examinations must agree as part of the application process:

1. The examination and all test questions are the exclusive property of the ABP and are protected by copyright law. Because of the confidential and proprietary nature of these copyrighted materials, I agree not to retain, copy, disclose, discuss, share, reveal, distribute, or use for exam preparation any part of these examination materials, including memorized, reconstructed and recalled items.

2. The following actions may be sufficient cause for ABP, in its sole discretion, to terminate my participation in an examination, to invalidate the results of my examination, to withhold or revoke my scores or certificate, to bar me from future examination, or to take other appropriate action:

3. The unauthorized possession, reproduction, disclosure, discussion, or distribution of any examination materials, including, but not limited to, examination questions, answers, reconstructed and recalled items at any time before, during, or after the examination.

Resident C: Were you surprised by the exam? How would you have studied differently?

Resident B: I don't know how I did yet, but I wish I would have studied some of the basic pathology and molecular 
concepts more; there were a lot of molecular questions. Some of the practical and image questions didn't ask for direct identification of a disease process, but asked about basic pathology concepts including pathogenesis and mechanisms of disease.

Discussion: Providing this type of information is appropriate. You can let others know what general topics are on the board examination and what books or resources were useful to study.

Resident A: I have heard that some people run out of time on the practical exam. Did you have time to go back and change your answers?

Resident B: I was pushed for time in a few sections. I wish I had reviewed the virtual slides that are provided on the $A B P$ Web site. Make sure you pace yourself and keep track of the time.

Discussion: Providing general information on test administration is also acceptable. Candidates are being examined on their competencies and knowledge in pathology, and information on timing, instructions, and test-taking strategy is appropriate.

Resident C: So were there a lot of questions about neuropathology? How about lymphomas?

Resident B: I only remember a few brain tumors, and the hematopathology was pretty tough. I seem to remember a lot of questions on breast and gastrointestinal pathology. However, I was prepared for these topics.

Discussion: The residents are still considered to be in a safe zone, and are not cheating. General information on coverage of various organ sites is appropriate.

Resident A: Do you remember any specific glass slides or images? It would be helpful to see the way the questions were worded, the history, the correct answer, and the various choices.

Resident B: I think there was a slide of cytomegalovirus in the lung; that was from a 30-year-old man with a recent transplant. There was also a photo of a fine-needle aspirate of medullary carcinoma of the thyroid from a 40-year-old woman. The photo showed mostly single cells, some spindled, and a few with inclusions. I don't think I can remember the exact wording of any question, and I don't think I am supposed to provide this anyway, as it might be cheating.

Discussion: Everyone should recognize that recalling the exact wording of a question, including choices, is cheating. However, is it appropriate to provide a recall list of diagnoses, images, and glass slides? Providing a detailed listing of glass slides or images is still considered recall and is not acceptable. To provide an exam with psychometric reliability and validity, the $\mathrm{ABP}$ and other certification boards use a certain proportion of repeat questions on subsequent exams. For this reason, the exam questions are protected by copyright law and considered valuable intellectual property; candidates with specific knowledge of past questions may gain an advantage in passing the examination. Providing detailed descriptions of morphology or patient history specific to the question means that the resident is no longer being tested on his/her abilities and has "insider information." The ABP uses criterion-referenced examinations in which the pass point is established by expectations of what a successful candidate is expected to know. The pass point is not norm based (a comparison of all candidate scores); thus, candidates without access to recall items are not technically placed at a disadvantage.

The decision as to where to draw the boundary between helpful and unprofessional behavior may at times seem indistinct to test takers. In these cases, thinking how a respected elderly friend or relative would judge the circumstances can be useful: would they approve of providing detailed information from past exams in order to improve chances of becoming certified, or would they want the individual to become certified based on competence, knowledge, and diagnostic abilities?

Resident C: I heard that the ABP is cracking down on cheating and I am not supposed to look at any test sample questions. Will the board review courses have to change what they do?

Discussion: Residency programs are encouraged to use study groups and didactic sessions to help prepare their residents to take exams. Simulated types of exam questions are appropriate for both residency didactic sessions and study groups, and can serve as useful teaching methods throughout training. Similarly, board review courses and references with sample exam questions are useful study aids, as long as the questions are not recalled items from actual board exams. The ABP Web site provides some sample questions that help residents prepare for specific question formats used in the examination. Finally the Resident InService Examinations administered by the American Society for Clinical Pathology help programs and trainees assess their progress and current medical knowledge.

Resident B: There were some lists of board remembrances in one of the file drawers in the resident office. We probably need to dispose of this file so we don't get into trouble in the future.

Discussion: Does this level of scrutiny for the ABP board examinations amount to a lot of unnecessary concern? Do we really have a problem? Many practicing pathologists acknowledge that files of exam remembrances were routinely available in the resident offices in many academic pathology departments in the past. However, increasingly these remembrances and recall items are being shared electronically and what was once hidden in a file drawer is now readily available on the Internet. In today's world, any computer files may become public information, and any allegations of cheating by physicians are likely to make the news.

Recent publicity and actions by other board organizations suggest that the public does not tolerate sharing of test items or remembrances on examinations. A June 2010 story in American Medical News (from the American Medical Association) reported that 139 physicians were sanctioned by the American Board of Internal Medicine for allegedly exchanging test questions from the board's certification exam. ${ }^{3}$ These physicians had participated in a commercial board review course and disclosed to the course officials the actual board questions. The sanctions included revocation of board certification or suspension of certification for 1 to 5 years. The board also sued the board review course and owners claiming copyright infringement and theft of trade 
secrets. Humayun Chaudhry, DO, president and chief executive officer of the Federation of State Medical Boards, is quoted in the story. He stated that physicians bring "disrepute" on the profession by exchanging board exam questions. "Cheating on a board certification exam is a serious matter which calls into question a physician's character," he said.

The radiology profession recently received unfavorable publicity concerning cheating on the American Board of Radiology (ABR) certification examination. A radiology resident complained about the availability of banks of recalled radiology test items on both a resident Web site and a shared military computer server. The allegations of widespread cheating by radiology residents were investigated in a documentary by CNN in January $2012 .{ }^{4}$

For years, doctors around the country taking an exam to become board certified in radiology have cheated by memorizing test questions, creating sophisticated banks of what are known as "recalls," a CNN investigation has found. The recall exams are meticulously compiled by radiology residents, who write down the questions after taking the test, in radiology programs around the country, including some of the most prestigious programs in the U.S. ${ }^{4}$

Gary Becker, MD, executive director of the ABR, was interviewed for this story. "Questions and answers have been memorized, sometimes verbatim, and contributed to extensive archives of old ABR test material that become the prize possessions of many residency programs," Becker said in the video, which appears on the board's Web site. "Accumulating and studying from lists of questions on prior examinations constitutes unauthorized access, is inappropriate, unnecessary, intolerable and illegal."

A video and a detailed policy are now available on the ABR Web site, and Dr Becker explains their policy:

Sharing recalled questions is inappropriate because it evidences unprofessional behavior on the part of the test taker. It violates the integrity of ABR's examination, and undermines the public's trust that the candidate has demonstrated competence and professionalism. The public has the right to expect that diplomates of the ABR have been certified because of their knowledge and demonstration of core competencies and not because of inappropriate access to ABR propriety test information. ${ }^{5}$

In response to concerns of the $\mathrm{ABP}$ over the use of recalled test items, the following statement was recently endorsed by the Council of the Association of Pathology Chairs (Peter J. Kragel, MD, e-mail communication, July 31, 2012):
Recording, sharing, and reviewing recorded questions from the American Board of Pathology examination represents unethical and, at times, illegal behavior. Each examinee pledges against the following as part of taking the examination: "transferring or receiving information relating to the contents or answers of the examination to or from another candidate or a third party before, during, or after the examination. This prohibition includes any transfer of information between a candidate and another person at any time during the examination, including breaks, and any reconstruction of examination questions and answers and the transfer of information concerning the same after the examination." Given recent breaches that have been described, the Association of Pathology Chairs wishes to remind all residents that such activity is wholly unacceptable, and requests that the Program Directors Section disseminate this information to its members by e-mail to in turn inform the residents in their programs.

The pathology profession needs to take a proactive position and agree that cheating will not be tolerated. Our image as a profession devoted to quality patient care depends on maintaining the trust of the public and other health care providers that we are competent and professional. Residency training programs and peer residents provide valuable didactics, training, and experiences that should prepare candidates to successfully pass the ABP examinations. Past practices of maintaining board remembrance files or distributing any recalled test items either electronically or through copied documents are unacceptable and this type of behavior needs to cease.

I wish to acknowledge Rebecca Johnson, MD, chief executive officer of the $\mathrm{ABP}$; Betsy Bennett, $\mathrm{MD}, \mathrm{PhD}$, past executive vice president of the ABP; Patrick Lantz, MD, 2013 president of the $\mathrm{ABP}$; and Margaret Grimes, MD, treasurer of the $\mathrm{ABP}$, for their helpful review of the manuscript.

\section{References}

1. Booklet of Information 2013. American Board of Pathology Web site. http:// www.abpath.org/BookletofInformation.pdf. Accessed January 30, 2013.

2. What board certification means. American Board of Medical Specialties Web site. http://www.abms.org/About_Board_Certification/means.aspx. Accessed December 7, 2012.

3. Krupa C. Physicians sanctioned in board cheating exam scandal. Amednews Web site. http://www.ama-assn.org/amednews/2010/06/21/prsa0621.htm. Published June 21, 2012. Accessed Dec. 7, 2012.

4. Zamost S, Griffin D, Ansari A. Exclusive: doctors cheated on exams. CNN Health Web site. http://www.cnn.com/2012/01/13/health/prescription-forcheating. Published January 13, 2012. Accessed December 8, 2012.

5. Becker G. ABR exam security video, May 2011 [video]. American Board of Radiology Web site. http://www.theabr.org/ExamSecurityPolicy. Accessed December 8. 2012. 